World Lumen Congress 2021 | May 26-30, 2021 |

Iasi, Romania

\title{
Scaling Up' the Social Impact of Innovation in Services - Significant Findings and Best Practice Examples from Specialty Research
}

\author{
Cristina PATRASCU
}

https://doi.org/10.18662/wlc2021/56

How to cite: Patrascu, C. (2021). Scaling Up' the Social Impact of Innovation in Services - Significant Findings and Best Practice Examples from Specialty Research. In A. Sandu (vol. ed.), Lumen Proceedings: Vol. 17 World Lumen Congress 2021 (pp. 552-558). Iasi, Romania: LUMEN Publishing House. https://doi.org/10.18662/wlc2021/56 


\title{
'Scaling Up' the Social Impact of Innovation in Services - Significant Findings and Best Practice Examples from Specialty Research
}

\author{
Cristina PATRASCU 1
}

\begin{abstract}
"Social innovation" have gained the focus of interest of many researchers and professionals preoccupied to find solutions to heay societal problems manifesting themselves as challenges or obstacles for public organizations in the field of services of general interest.

The present article explores the specialty research on the impact of social innovation concentrating on the most recent trends and concepts that better describe the ways that can lead to the "diffusion" of social innovation, particularly in the domain of services that are designed with the goal to ensure a higher quality life for all citizens. The main objective of our paper is to contribute to the conceptual field of innovation, by presenting a clear definition and by highlighting the newest trends in research. We also tried to identify what are the possible strategies to be applied by stakeholders in order to ensure the process of scaling up, bringing examples that prove the relevance of this concept in the field of public services.

In light of recent developments in the field of social innovation, we consider that both research and practice related to ,scaling up" need further evolution and more efforts in order to become solid points of reference for all interested parties. At the same time, the development of rigorous systems of evaluation of the effects and impact of innovation is strongly needed.

The methods used are mainly qualitative, based on the evaluation of the specialty literature on innovation in services, and comparative, applied to highlight similarities and differences between various cases of innovation in the social sector that may be transferred in the public sector.
\end{abstract}

Keywords: Social innovation, 'scaling up', diffusion, impact, public service.

\section{Introductory remarks}

The present article explores the specialty research on the impact of social innovation concentrating on the most recent trends and concepts that better describe the ways that can lead to the "diffusion” or ,growth" of social innovation, particularly in the domain of services that are designed and provided to guarantee a higher quality life for all citizens. One of the main findings to be extracted from a vast and (continuously) growing literature on the evaluation of innovation is that the concept of „scaling” or „scaling up” has become more and more present in various

\footnotetext{
${ }^{1}$ PhD Lecturer, „Dunarea de Jos” University, Galati, Romania, cristina.patrascu@,ugal.ro
} 
papers and studies, to the point of being considered a "dominant framing" (Davies \& Simon, 2013) in the analysis of the results and success of social innovation.

Innovation has come to be considered as a very promising tool that many governments and other social actors use with the aim to find answers to many of the difficult and growing problems of today's society. Given this strong interest, a growing body of research and literature has developed and created the theoretical terminology and methods of analysis. Innovation is considered and analysed today not only in its technological aspects, but its vocabulary has expanded to include „social innovation” as a fundamental concept. A newer and important branch of research in the field of innovation and social innovation has become the evaluation of impact, since monitoring and establishing the results and effects of innovation has to be a significant stage of the innovation process. There are also many concerns regarding the way innovations, particularly in the complex field of services and services' supply, can be transformed into models that can be disseminated and replicated within various fields and organizations.

\section{In search of a definition: exploring specialty literature}

Innovation as a concept has been explored and defined by a great variety of researchers, not always in rigorous ways, this is why anyone studying or writing on the topic has to be very careful as to the choice of the terms in which innovation is defined and analysed. Sometimes definitions overlap or lack conceptual precision, so the researcher must pay attention to the selection of these definitions. For the purpose of this article, definitions from the European Commission's Guide to Social Innovation (2013) and the Oslo Manual (2018), will be used.

According to the Oslo Manual (4th edition): 'An innovation is a new or improved product or process (or combination thereof) that differs significantly from the union's previous products or processes and that has been made available to potential users (product) or brought into use by the unit (2018, p. 60). In this edition, the Oslo Manual tries to make a difference from its (also much cited) previous one of 2005, and elaborates a general definition of social innovation, so that it can be applied in both private and public sector.

Another relevant definition, that we consider relevant, has been chosen from the European Commission's Guide to Social Innovation (2013). It is interesting that the document elaborates on the 'attractiveness' of this term and states that this attractiveness must be generated, among other things, by its possibility of being used as an 'umbrella concept' for 'inventing and incubating solutions...in a creative and positive way' (European Commission, 2013, p. 5). In this study, social innovation is defined as 'the development and implementation of new ideas (products, services and models) to meet social needs and create new social relationships or collaborations' (European Commission, 2013, p. 6). It has to be pointed out that the definition of social innovation elaborated by the European Commission brings to the fore the 'social' dimension, since in its view innovations may be considered social only if they are 'social in both their ends and their means' (European Commission, 2013, p. 6). 
The second fundamental concept of our analysis that we will be focusing on, in the next lines, is ,scaling up”. In the last decade, this term has been stirring much curiosity and has been applied predominantly in the field of social services and healthcare, but it is also building its way into the field of public services. For this concept too, we have discovered various interpretations as well as various shades of meaning within the many sources that make efforts at analysing the concept.

A significant statement to be made, before presenting several definitions of the notion of "scaling up", is that the focus must be placed on replicating and expanding the „social impact” of innovation, (acknowledged to be more abstract and harder to assess) rather than on quantitative results. As many scholars have pointed out, scaling social impact is one of the most difficult goals to attain in both practice and research (Capgemini Research Institute, 2020; Davies \& Simon, 2013; Han \& Shah, 2020; McPhedran et al., 2011). Whereas literature on scaling up innovations is older, research on scaling the social impact of innovation is a 'promising new paradigm' (McPhedran et al., 2011, p. 145).

Therefore, 'scaling up' or more simply 'scaling' of a social innovation may be defined as the process that 'offers the potential to greatly expand the social value of innovation to a greater number of beneficiaries' (Bloom \& Smith, 2010, p. 127).

In similar terms, in the field of innovation in healthcare services, including public sector healthcare, the World Health Organization (WHO) carried out an informed and valuable work, resulting from its long years of research based on experience and practice in the field. The organization expressed its proficient views in several relevant documents. In one of these documents, WHO defines scaling up as 'deliberate efforts to increase the impact of successfully tested health innovations so as to benefit more people and foster policy and programme development on a lasting basis' (2010, p. 2). In a more recent report, the same organization states that: 'Scaling up means to expand or replicate pilot or small-scale projects to reach more people and/or broaden the effectiveness of an intervention. The procedure is close to diffusion, dissemination and implementation of innovation.' (2016, p. xi). Along the same lines, the „diffusion" of social innovation as part of the meaning and also process of 'scaling up' was mentioned several years before by Davies and Simon (2013). The authors emphasized that „scaling up” included both the aspects of "growth” and „diffusion” of innovation. Looking a little bit further back in time, we must acknowledge that the research in this field took up and build upon the idea of diffusion from the influential work of Rogers, whose book Diffusion of Innovations, published in 1962, reached its 5th edition in 2003 and continues to inspire scholars and students around the world.

The specialty literature on the theme of 'scaling' has expanded in recent years, providing a rich terminology deriving from it. For instance, in a recent article, we can find the term 'scalability' understood as 'the ability of a health intervention shown to be efficacious on a small scale and/or under controlled conditions to reach a greater proportion of the eligible population, while retaining effectiveness' (Milat et al., 2013, p. 289; Milat et al., 2020, p. 2). 'Scalability' appears also in the cited report elaborated by WHO (2016). Thus, scalability is used by the authors with 
the meaning of spreading and disseminating a solution that worked for one type of problem and making it feasible for other (similar) type of problems or even applying on another level and adjusting it to benefit a greater number of people.

Definitions of 'scaling up' or 'scalability' appear in many other studies, but we will only refer here to the most recent ones, such as: Albury et al. (2018) or Ben Charif et al. (2021).

\section{3. 'Just copy what works' (Warburton, 2018) - What works somewhere, works everywhere... or doesn't it?}

Innovation, as unbelievable as it may seem, does not 'just' spread and is not 'naturally' embraced and cultivated by organisations and people! Moreover, 'scaling up' tends to be a problematic process that requires planned, knowledgeable, collaborative, and perseverant actions spanning over a certain period of time. As promoters of innovation point out: '...managing the diffusion, dissemination and implementation of innovative and effective public health interventions are ongoing challenges for the public health workforce' whereas 'transferring successful smallerscale initiatives to other places or to a larger scale... is challenging' (WHO, 2016, p. $1)$. The main reasons of these challenges are the existing 'differences between settings' and „contexts”, together with the 'different characteristics of users and user needs' (WHO, 2016, p. 1). An analogous observation is aptly 'summarised' in another study which gathers evidence against wishful thinking expressed as: 'Just copy what works' (Warburton, 2018). This is, in fact, simply not possible and we share Warburton's opinion, because as he highlights: '... encouraging the take-up of new ideas or ways of working is often much harder and that even when it happens, what works for one service in one place at one time, often results in different outcomes in a different context' (Warburton, 2018).

However, these obstacles have not discouraged innovators from pursuing their work and, as literature and experience prove it, there are innovations that 'do spread' and are regarded as best practice examples. For instance, some of these innovations range 'from checklists and care bundles to telehealth and patient selfmanagement programmes', complemented by many others, such as: 'Enhanced Recovery after Surgery (ERAS), High sensitivity troponim testing, Implantable Cardioverter-Defibrillators (ICDs), Improving Access to Psychological Therapies (IAPT)' (Albury et al., 2018, p. 1). Another example which shows how innovations were successfully transferred from a broader level to local levels is the European Union's DART project (Declining, Aging and Regional Transformation). Through the network created within this project, innovative ideas were applied at various other regional levels in the EU, one such region being Lower Austria (WHO, 2016, p. 7).

In as far as other types of services in the public sector are concerned, it becomes evident that the concept of 'scaling up' has not been used only in relation to healthcare or social care, but also to refer to innovation in the public sector, as several sources on spreading of innovations clearly substantiate. There are first of all, the references to scaling up the social impact of innovations in the public sector in the reports elaborated by BEPA (Bureau of European Policy Advisors), 
published in 2011 and 2014. For instance, while recognizing the existence of ' $F e w$ robust models for scaling up social innovations' across EU member states (2011, p. 9), BEPA emphasizes the direct link between the process of scaling up social innovation and 'networking the stakeholders and promoting public-private partnerships, developing common methodologies for measuring impact and social return' (2011, p. 7). The process of scaling up appears thus to be a concerted effort of all actors, from both public and private sector, intended to expand the beneficial effects for a greater number of people, in a wide array of services, including education. In this domain, an example of 'scaling up' of an innovation is offered by the project known as 'second-chance schools', a model applied 'in many areas in France' (2011, p. 33). Then, in another BEPA report the concept of 'scaling up' is used in relation to 'innovative public programmes addressing important policy issues' (2014, p. 34), showing that this organisation uses the concept to cover innovations initiated by both public or private organisations.

Some scholars advance the idea of an 'ecosystem of scaling social impact' and discuss the connection between 'the role of institutional infrastructure and government policy' and 'the process of scaling up' (Han \& Shah, 2020, p. 224). Others argue that 'the route to greater impact lay in changing institutions, policy and law - "scaling up" to change the "rules of the game" (Moore \& Riddell, 2015, p. 2). We consider that such perspectives are more creative and inspiring, as they bring to the fore the transformative nature of the process of scaling up innovations in order to respond to and fulfil complex social needs, that are challenging and very dynamic at the same time.

\section{Conclusions}

„Scaling up" remains a topic that still needs systematic research in order to be perfected, as there are no solid models to be used in practice to enhance the impact of social innovations. Specialty research has made serious progress in recent years, but there is still need to deepen some of its directions or paths. At the same time, there are some areas in which it remained underdeveloped, particularly in relation to finding appropriate schemes or algorithms based on significant indicators to really make possible the scaling up of the social impact of public sector innovation. Another weakness consists in the lack of ability to create the best instruments to institutionalise innovation in a sector that is not as open to taking risks and experimenting as say, for instance, the private one.

It has to be said that the interest in social innovation, as a theme in itself, and in the process of growth and diffusion of innovative projects, was greatly influenced by the ongoing pandemics that changed humankind and public life in numerous ways. Irrespective of the semantic variations of the concept, the necessity and importance of ,scaling up”, seem greater than ever before and we consider that researchers have made efforts to integrate these dramatic changes in their work. In this sense, we may say that specialised literature in this domain made its contribution to the development of this scientific field constructing terminologies and establishing methods of analysis, gathering and comparing data and examples of 
best practices. The most needed action, in our opinion, would be in the field of networking and finding the best ways of collaboration between multiple stakeholders across sectors or activities and anchoring research deeply in the life of community, to make it resonate with its needs and pace of development. Otherwise, it would remain too abstract and aloof, „ivory-towerish” (our own terminology innovation) in its resolve to serve only a limited academic interest, instead of becoming a contributor to a greater interest.

In light of all these findings, we sustain the idea that 'scaling up' innovations is not a process of simply replicating and spreading new ideas or products, but a more complex and, inherently, cooperative process, one that involves agents across sectors (public, private, not-for-profit) or even individuals, and that affects and transforms in a profound way people, organizations, structures, relations and mentalities.

\section{References}

Albury, D., Beresford, T., Dew, S., Horton, T., Illingworth, J., \& Langford, K. (2018). 'Against the odds: Successfully scaling innovation in the NHS'. Innovation Unit.

Ben Charif, A., B., Plourde, K., V., Guay-Belanger, S., Zomahoun, H. T. V., Gogovor, A., Straus, S., Beleno, R., Kastner, K., McLean, R. K. D., Milat, A. J., Paquette, J.-S., Geiger, F., Legare, F., \& The RePOS Network. (2021). Strategies for involving patients and the public in scaling-up initiatives in health and social services: protocol for a scoping review and Delphi survey. Systematic Reviens, 10: 55. https://doi.org/10.1186/s13643-021-01597-6

Bloom, P., N., \& Smith, B., R. (2010). Identifying the Drivers of Social Entrepreneurial Impact: Theoretical Development and an Exploratory Empirical Test of Scalers. Journal of Social Entrepreneurship, Taylor \& Francis Journals, 1(1), 126-145, https://ideas.repec.org/a/taf/jsocen/v1y2010i1p126-145.html

Bureau of European Policy (BEPA). (2014). Social innovation: a decade of changes. Publications Office of the European Union. http://doi.org/10.2796/27161

Bureau of European Policy (BEPA). (2011). Empowering people, driving change: Social Innovation in the European Union. Publications Office of the European Union. http://doi.or/g10.2796/13155

Capgemini Research Institute. (2020). 'What's the Big Idea? Why most innovations fail to scale and what to do about it?". https://www.capgemini.com/research/scaling-innovation/

Davies, A., \& Simon, J. (2013). How to grow social innovation: a review and critique of scaling and diffusion for understanding the growth of social innovation. Paper prepared for the $5^{\text {th }}$ International Social Innovation Research Conference, September 2013, Oxford, The Young Foundation. https://youngfoundation.org/wpcontent/uploads/2013/11/Davies-Simon Growing-social-innovation ISIRC2013.pdf

European Commission. (2013). Guide to Social Innovation. http://doi.org/10.2776/72046

Han, J., \& Shah, S. (2020). The Ecosystem of Scaling Social Impact: A New Theoretical Framework and Two Case Studies. Journal of Social Entrepreneurship, 11(2), 215-239, http://doi.org/10.1080/19420676.2019.1624273 
McPhedran Waitzer, J., \& Paul, R. (2011). Scaling Social Impact: When Everybody Contributes, Everybody Wins. Innovations: Technology, Governance, Globalization, 6(2), 143-155.

https://econpapers.repec.org/scripts/redir.pf?u=http $\% 3 \mathrm{~A} \% 2 \mathrm{~F} \% 2 \mathrm{Fwww}$.mitpress journals.org $\% 2 \mathrm{Fdoi} \% 2 \mathrm{Fpdfplus} \% 2 \mathrm{~F} 10.1162 \% 2 \mathrm{FINOV}$ a $00074 ; \mathrm{h}=$ repec:tpr:innt gg:v:6:y:2011:i:2:p:143-155

Milat, A., Lee, K., Conte, K., Grunseit, A., Wolfenden, L., van Nassau, F., Orr, N., Sreeram, P., \& Bauman, A. (2020). Intervention Scalability Assessment Tool: A decision support tool for health policy makers and implementers. Health Research Policy and Systems, 18:1. https://doi.org/10.1186/s12961-019-0494-2

Milat, A.J., King, L., Bauman, A., \& Redman, S. (2013). The concept of scalability: increasing the scale and potential adoption of health promotion interventions into policy and practice. Health Promotion International, 28(3), 285-298. https://doi.org/10.1093/heapro/dar097

Moore, M. - L., Riddell, D. J. (2015). Scaling out, Scaling up, Scaling deep: Advancing systemic social innovation and the learning processes to support it. The J. W. McConnell Family Foundation. https://mcconnellfoundation.ca/wpcontent/uploads/2017/08/ScalingOut Nov27A AV BrandedBleed.pdf

Rogers, E. M. (2003). Diffusions of Innovations (5th ed.). Free Press.

OECD/Eurostat (2018). Oslo Manual 2018. Guidelines for Collecting, Reporting and Using Data on Innovation (4th ed.). OECD Publishing. https://doi.org/10.1787/9789264304604-en

Warburton, W. (2018). Foreword. In Albury, D., Beresford, T., Dew, S., Horton, T., Illingworth, J. \& Langford, K. (Eds.), Against the odds: Successfully scaling innovation in the NHS. Innovation Unit.

World Health Organization (WHO). (2016). Scaling up projects and initiatives for better health: from concepts to practice. https://www.euro.who.int/ data/assets/pdf file/0004/318982/Scaling-upreports-projects-concepts-practice.pdf

World Health Organization (WHO). (2010). Nine steps for developing a scaling-up strategy.https://www.who.int/reproductivehealth/publications/strategic approach/ $\underline{9789241500319 / \mathrm{en} / 00319}$ 